\title{
The Consequences of Fatherhood Transition Among Disadvantaged Male Offenders: Does Timing Matter?
}

\author{
Chongmin $\mathrm{Na}^{1}$
}

Received: 31 July 2015 / Revised: 16 November 2015 / Accepted: 15 December 2015 /

Published online: 15 January 2016

(C) Springer International Publishing AG 2016

\begin{abstract}
Objective Drawing on a relatively understudied population of disadvantaged male offenders, this study assesses potentially differential consequences of having a first child under different social contexts such as timing of an event.

Methods After determining the effects of fatherhood transition on offending and other proposed mediators at different stages of life (late adolescence vs. early adulthood) by adopting propensity score matching (PSM) and additional regression adjustment, mediating processes are assessed explicitly by employing multiple mediator models within a structural equation modeling (SEM) framework.

Results This study finds that having a first child has no beneficial effects on teen fathers' lives, whereas becoming a father during early adulthood has transformative potential. Crime-generating effects of teen fatherhood are significantly related to the changes in immediate and proximate correlates of crime such as lifestyles and delinquent peer association.

Conclusion These findings support the prediction from life course perspectives which posit that the impact of salient life events is not homogeneous but varies substantially by the timing of a transition. Further understanding of not just how timely arrival of turning points exerts influence on the reduction in subsequent offending but also why untimely transitions do not inhibit or even facilitate future offending would be fundamental to a more complete understanding of criminal desistance.
\end{abstract}

Keywords Fatherhood $\cdot$ Offending $\cdot$ Turning point $\cdot$ Timing

Chongmin $\mathrm{Na}$

cna@jjay.cuny.edu

1 Department of Criminal Justice, John Jay College of Criminal Justice, City University of New York, New York, NY 10019, USA 
Over the past decades, criminologists have given considerable attention to the consequences of major life events for criminal involvement and its pattern over time (e.g., [1, $2]$ ). Although there is a body of literature that supports the key predictions from lifecourse explanations of crime, the empirical research on the role of "turning points" has been limited to the transitions into marriage [3-6], employment [2, 7-10], and military service $[2,11,12] .{ }^{1}$ Interestingly, a limited but growing body of work demonstrates that other salient life events such as becoming a parent [11, 15-17] can also "give shape to life stages, transitions, and turning points" ([18]: 17) through the same causal mechanisms of the other turning points articulated in the previous research. In particular, qualitative studies drawing on the retrospective accounts of changes from ethnographic interviews have consistently documented the crime-inhibiting effects of becoming a parent among samples with diverse social and cultural backgrounds (e.g., [1, 19, 20]). Quantitative research, on the other hand, does not provide a decisive conclusion to suggest that parenthood transition might have different meanings and implications for individuals with different socio-demographic backgrounds (e.g., age, gender, race/ethnicity, SES) and relationship contexts with their romantic partners or children $[15,16,21-24]$. For example, while life-course perspectives have long acknowledged that the meaning and consequence of a turning point can vary substantially by the timing of a transition [2, 12, 18, 25], an in-depth understanding of whether the transition into parenthood at different stages of life has a beneficial or even deleterious effect remains elusive, as most research has focused on the period of either adolescence or adulthood or has lumped them together. By emphasizing age-graded roles and social transitions, life-course literature suggests that normative timing and sequencing of role transitions are important in shaping subsequent pathways of the life course. Thus, the same event or transition may lead to inherently different life outcomes depending on how successfully individuals embrace and adapt to the new roles and expectations. In particular, transitioning too early or too late to what is commonly viewed as a prosocial institution may in fact generate or enhance later difficulties in successful social adaptation and development (e.g., [9, 12]).

The lack of attention afforded to the parenthood transition as a potential turning point and the importance of its timing is noteworthy given that childbirth outside of marriage, especially at an earlier stage of life, is increasingly prevalent and even becoming normative in the contemporary society. Family and marriage research suggests that the family structure has changed dramatically over the past decades, characterized by decreased overall marriage rates and delayed first marriages [26]. Not surprisingly, nearly one third of children are now born outside of marriage, especially among disadvantaged minority populations [27]. Given such changes in norms regarding acceptable types of romantic relationship and family structure among young couples, the age-graded roles and the sequencing of role transitions that have traditionally been valued may need to be reconsidered.

In particular, socio-economically disadvantaged minorities and serious offenders, who are already marginalized from the conventional social institutions, may attempt to make up for their lack of connectedness and fulfilling experiences by transitioning into

\footnotetext{
$\overline{{ }^{1} \text { Recently, efforts are being made }}$ to extend the concept of turning points to other life events such as gang membership (e.g., [13]) or school dropout (e.g., [14]).
} 
parenthood, especially at early stages of life - although it is possible that the same qualities that resulted in too early childbearing (e.g., low self-control) may continue to generate new sources of stress within family relationships ([28]: 5). While the support for marriage is still the norm across different socio-demographic groups [19, 26], there is a substantial heterogeneity in the prevalence and the timing of marriage among general populations, with socially disadvantaged minorities and serious offender groups experiencing a larger gap between marital intention and marital behavior [19]. In the face of structural barriers to landing a good marriage or employment - at least in a timely manner-young couples living in urban, poor, and predominantly minority neighborhoods, often with serious offending histories, tend to attribute more importance to becoming a parent as an essential transition to adult roles and identities than getting married [20]. While fathers often testify that they enthusiastically assume their new roles and responsibilities and adjust their lifestyles accordingly (e.g., [20]: 54-55), research suggests that parenthood transition has a greater potential for reshaping the lives of women than of men [29, 30]. Indeed, the effect of parenthood transition is inevitably contingent on the within-individual changes in routine activities and physical/emotional bonds to child and other family members resulting from the "structured role stability" ([1]: 145). While young fathers tend to readily adjust their lifestyles and assume the parental roles rather than flee from financial and relational responsibilities [31, 32], at least initially [33, 34], economic hardship, reincarceration, family conflicts, and mistrust undermine the stability of these positive changes ([35]: 77). Accordingly, beneficial effects of childbirth do not have a lasting impact but tend to be restricted to the period when fathers actively assume paternal roles and responsibilities $[32,36] .^{2}$ Most of all, considering that fathers can more easily deny/reject their parenting roles - or sometimes do not even know that they have fathered a childthan mothers, it is plausible to assume that fatherhood plays a less influential role in the process of desistance than motherhood ([16, 23]: but see [24] for conflicting results).

Lastly, although recent empirical studies present robust findings after substantially controlling for self-selection effects by employing longitudinal panel data and rigorous methods for establishing causality (e.g., fixed-effects models: [15]), far less is known about the specific mechanisms through which parenthood transition exerts effects on subsequent offending. Some ethnographic studies explored this linkage based on the retrospective testimonies from mothers who successfully changed their behavioral patterns after giving birth (e.g., [19]), but more systematic research using understudied populations (e.g., disadvantaged male offenders) is needed under a unified theoretical framework. In particular, such direct investigations of causal mechanism across different stages of life would add insights to why timing of an event matters in the desistance process.

Targeting a relatively understudied group of individuals (serious male offenders who are predominantly disadvantaged minorities), the current study explores potentially differential effects of having a first child under different social contexts such as timing of an event. After determining the impacts of fatherhood transition on offending and other proposed mediating factors at different stages of life (late adolescence vs. early adulthood) using propensity score matching (PSM) and

\footnotetext{
$\overline{2}$ Interestingly, ([32]: 149) suggest that such deterioration is less dramatic for African American fathers.
} 
additional regression adjustment, mediating processes will be assessed explicitly by employing multiple mediator models within a structural equation modeling (SEM) framework.

\section{Literature Review}

\section{Theoretical Framework: Laub and Sampson [1]'s Revised Life Course Theory}

Sampson and Laub [2] initially posited that changes in offending patterns over a life course are possible as individuals experience major turning points. A decade later, Laub and Sampson [1] modified and expanded their original theory to better account for the causal mechanisms through which major turning points in life affect patterns of persistence in offending and desistance from crime. In this revised theory, they made it clear that "offenders desist as a result of a combination of individual actions (choice) in conjunction with situational contexts and structural influences linked to important institutions that help sustain desistance" (145). For example, the structured role stability induced by salient life events cuts off offenders from their immediate crime-friendly environments, enhances informal social control and social bond, and offers them a new script for the future (see [1]: 145-149 for more detail). While criminological research has primarily focused on some of the key turning points highlighted in a series of works by Sampson and Laub (e.g., marriage, employment, and military service), more recent studies document the applicability of these general mechanisms to other life events such as parenthood [4, 15-17] because becoming a parent can create new social roles/ interactions, life patterns, and identities through enhanced physical and emotional bonds to prosocial individuals such as partners and children ([6]: 469). However, extant research does not provide a decisive answer regarding the consequences of the transition into parenthood (fatherhood in particular), not to mention the specific processes of how it affects subsequent offending behaviors.

\section{Timing of Transition}

Although relatively little attention has been given in existing research, one of the key components underlying the life-course dynamics is the timing of the role transition and its implication. Sampson and Laub [2] begin their book by emphasizing "life-course analyses are often characterized by a focus on the duration, timing, and ordering of major life events and their consequences for later social development." In a similar vein, [25] clearly posits that the timing of life transitions has long-term consequences through effects on subsequent transitions and "the developmental impact of a succession of life transitions or events is contingent on when they occur in a person's life." Timing of the culturally defined age-graded roles marked by a sequence of major life transitions is crucial in understanding the potentially heterogeneous effects of the same events on a variety of life outcomes. Accordingly, the social meaning of age should be adopted in the explanation of crime patterns because life-course theories posit that crime declines with age not just because of natural aging or the maturation processes but also because of the changes in structural, situational, and internal factors associated with age. 
"It was not the achievement of any particular age, but rather the achievement of adequate maturation regardless of the chronological age at which it occurred that was the significant influence in the behavior change of our criminals" ([37]: 81).

It is the successful adaptation to major life transitions in a timely manner that drives all the beneficial effects implicated in turning points. Accordingly, a successful transition to the parental role and identity results in a shift in behavioral patterns from the ones that characterize adolescence to those that characterize adulthood. In this vein, assuming paternal responsibilities prematurely would not necessarily affect the causal mechanisms of desistance (e.g., changes in social bond, routine activities, peer association, identity) as predicted by Laub and Sampson [1]. Indeed, the variability in the consequences of fatherhood observed across the different timing of an event may result from differential motivation or readiness for change. Recently, it is claimed that offenders must undergo some critical "cognitive and emotional changes" before turning points or hooks for changes become salient [38, 39]. In a similar vein, Paternoster and Bushway [40] explicitly posit that "self-identity and intentional self-change" are critically involved in the desistance process.

\section{Heterogeneous Effects}

With some notable exceptions (e.g., [24]), research suggests that the transition into parenthood plays a more central role in reshaping the lives of women than of men [29, 30]. Accordingly, the literature on men's transition to fatherhood is sparse and most criminologists have examined the impact of a transition to motherhood (e.g., [15]). Research suggests that poor minority males enter into casual romantic relationship at an unusually early stage of life (see Tach and Edin [35] for a review), which results in early pregnancy and childbirth within a non-marital relationship. Such premature romantic partnership tends to be less stable and relatively short-lived, and it is widely accepted that fatherhood is less likely to become central to the father's lives and identity than motherhood. Although traditional definition of father's role as a primary financial caretaker is becoming obsolescent and fathers also make physical and emotional efforts to get involved in children's lives and caretaking practices in the general population ([41]: 669), the unique facets of fatherhood among young disadvantaged men (e.g., becoming a father outside of marriage, cohabitation, or even stable romantic relationship) still limit continuous fatherchild interaction especially when the relationship with child's mothers ends.

In addition, marriage rates have recently declined dramatically and the proportion of first births outside marriage (e.g., by cohabiting couples) continues to increase inside and outside the USA [16], especially for low-income minorities [20]. ${ }^{3}$ Accordingly, many poor minority parents who have not been successful in establishing strong and stable social bonds due to structural barriers may strive to make up for their lack of connectedness through an early transition into parenthood. In this vein, Matsueda and Heimer ([42]: 179) claimed that "having a child may have very different meanings for an impoverished inner-city family than an affluent family." Despite such potentially

\footnotetext{
${ }^{3}$ For example, African American women with non-marital childbirths are found to be $25 \%$ less likely to get married by the age of 40 than white women [27].
} 
heterogeneous effects of parenthood transition across distinct subgroups of a general population, extant research has focused exclusively on estimating the population average treatment effect (PATE), which tends to mask important heterogeneous effects across specific segments of a broad population.

\section{The Current Study}

The current study attempts to address four major gaps in the extant research. First, there are few quantitative studies that successfully assess the impact of having a first child on subsequent offending and other aspects of life after accounting for most relevant preexisting differences between the parent and non-parent groups. Second, most empirical research examined a general population or female-only samples and failed to provide a convincing evidence for a more policy-relevant subgroup of the general population such as highly disadvantaged male offenders. Third, most studies did not explicitly investigate the heterogeneous effects of parenthood transition that may vary substantially depending on the timing of an event. Lastly, the causal mechanisms of precisely how becoming a parent at different stages of life exerts changes in subsequent offending patterns remain speculative.

Focusing on a relatively homogeneous group of individuals — serious male offenders who are predominantly disadvantaged minorities - this study assesses the contribution of the transition to fatherhood to the changes in offending and other proposed mediators by adopting a "potential outcome" model of causality. In doing so, two sets of data are created and analyzed to examine differential effects of becoming a father that may vary by the timing of acquiring parental status. More importantly, multiple mediator models are employed to decompose the total effect into direct and indirect effects and better disentangle the causal mechanisms underlying the fatherhood effects. Specific hypotheses include:

H1. The transition to fatherhood during adolescence is not associated with the reduction in subsequent offending behaviors.

H2. The transition to fatherhood during adolescence does not have beneficial effects on the proposed mediators.

H3. The transition to fatherhood during young adulthood is associated with the reduction in subsequent offending behaviors

H4. The transition to fatherhood during young adulthood has beneficial effects on the proposed mediators.

H5. The proposed mediators at least partially mediate the observed impact of fatherhood on subsequent offending behaviors.

\section{Project Design and Implementation}

\section{Data}

The current study examines a subset of data collected from the Pathways to Desistance study (http://www.pathwaysstudy.pitt.edu/). The study recruited 1354 adjudicated 
youths from 14 to 17 years of age while they were being processed in the juvenile and adult court systems in Philadelphia, PA $(n=700)$, and Phoenix, AZ $(n=654)$. A projective longitudinal panel design was employed to examine the process of desistance from crime and other within-individual changes in a wide array of life domains such as cognitive, psychological, and social development as the individuals transitioned from adolescence into early adulthood. The study participants completed the baseline and follow-up interviews at 6-month intervals for the first 3 years and annually thereafter (in total, eleven data collections were completed including the baseline and follow-up interviews at $6,12,18,24,30,36,48,60,72$, and 84 months) over the course of the study period. The sample was composed predominantly of minority $(73 \%)$ and male ( $86 \%$ ) youths. Out of these 1354 cases, only male subjects who had complete information about the fatherhood status at the baseline and follow-up interviews and did not report any children at the baseline were retained in each of the adolescent $(n=864)$ and young adult $(n=476)$ samples to distinguish between fatherhood and non-fatherhood transition groups. For direct comparison of potentially differential effects of a precocious transition to fatherhood from one that is more age normative, two subgroups were created by splitting the sample in such a way that maximizes the age difference of these groups. In addition, considering that mediation analyses require at least three waves to establish the temporal sequence of variables, the adolescent sample was created based on the baseline, 12-, and 24-month follow-ups whereas young adult sample was created using 60-, 72-, and 84-month follow-ups. Among those who did not report any children in the previous year, 64 out of 864 (7. $41 \%$ ) adolescents and 69 out of 476 (14.50\%) young adults transitioned into fatherhood for the first time in their lives during the first and the sixth year of the study, respectively. Age at first birth ranged from 15 to 19 years for the adolescent sample and from 20 to 24 years of age for the young adult sample.

\section{Measures}

\section{Independent Variables: Becoming a Father}

The subjects' status as a father was measured by the self-reported number of children during the recall periods ("How many children have you had during the recall period?"). Considering that the collateral reports from the subjects' parents or friends were limited to the first 3 years of the study (adolescence period), self-reports were used as an indicator of the fatherhood transition at different stages of life.

\section{Dependent Variable: Self-Report Offending}

Self-Reported Offending (SRO) was used to measure the subject's level of offending behaviors. The SRO consisted of 22 items collected at the baseline and each of the follow-up interviews. Two different SRO scores were used as primary outcomes: "frequency" and "variety" scores. The frequency score was created by summing the number of unique criminal acts committed within the recall period regardless of the type. The variety score was calculated as the proportion of endorsed items divided by the total number of items to which a subject gave either a "yes" or "no" answer. In addition, each offending score 
was further divided into two subcategories (aggressive and income-generating) ${ }^{4}$ to check if the consequences of fatherhood transition are different across types of offending.

\section{Background Characteristics}

Demographic Covariates The key demographic characteristics used to create an equivalent counterfactual group for the fatherhood transition group included age, race/ethnicity, IQ score, the number of biological parents in the household, and the absence of adults in the household. The socioeconomic status of the subject's parent was assessed by two items: (1) the level of education attained by biological parents and (2) the social position of parents computed based on both education and occupation. The criminal history of family members was measured by the number of family members that had ever been arrested. The subject's employment and marriage (the latter is available only for young adults) statuses were also included to reduce potential bias.

Early Problem Behaviors Subject's prior offense history was measured by the official data as follows: (1) total number of petitions and (2) age at first petition. As a symptom of risky sexual behaviors that are known to predict the likelihood of childbirth, multiple indicators were included such as (1) number of sexual partners, (2) age at first sex, (3) number of one-night stands, (4) ever in more than one sexual relationship at a time, and (5) ever been unfaithful to romantic partner. As indicators of intimate romantic relationship which also affects the chances of becoming a parent, the nature of romantic relationships was measured such as (1) longest period of time in one relationship and (2) ever been deeply in love.

\section{Other Theoretical Control Variables}

A variety of other theoretically and empirically relevant characteristics of individuals (social control/bond, rational choice, psychological development, low self-control, and social learning) that are known to be associated with both fatherhood transition and offending were included in the model to minimize the selection bias. Table 1 summarizes these variables.

\footnotetext{
${ }^{4}$ Eleven SRO items (destroyed/damaged property, set fire, forced someone to have sex, killed someone, shot someone bullet hit, shot at someone no hit, took by force with a weapon, took by force without a weapon, beat up someone serious injury, in a fight, beat someone as part of gang) and ten SRO items (broke in to steal, shoplifted, bought/received/sold stolen properties, used check/credit card illegally, stole car or motorcycle, sold marijuana, sold other drugs, been paid by someone for sex, took by force with a weapon, took by force without a weapon) were used to create aggressive and income-generating offending scores, respectively. Due to some conceptual overlap between these two sub-categories, two SRO items (took something by force with a weapon and took something by force without a weapon) were included in both scores (see http://www. pathwaysstudy.pitt.edu/codebook/sro-sb.html).
} 
Table 1 Summary of control and mediating variables

\begin{tabular}{llr}
\hline Measure & Construction & $\begin{array}{c}\alpha \text { Example Item } \\
\text { baseline) }\end{array}$ \\
\hline
\end{tabular}

\section{Social control/bond}

Parental knowledge

Parental monitoring

Maternal warmth

Maternal hostility

Aspirations for success*

Expectation for success*

Motivation for success*

Social support (diversity score)

\section{Community} involvement

Social capital (social cohesion)

Social capital (social integration)

Social capital (opportunity)

Religion frequency

Religion importance

Rational choice

Certainty of
punishment
(you)
(you)

Certainty of punishment (others)
5-Item scale assessing parental knowledge about the subject's time spending

4-Item scale assessing parental monitoring of subject's behaviors

9-Item scale assessing affective parental-adolescent relationship

12-Item scale assessing hostile parental-adolescent relationship

14-Item scale assessing commitment to achieving success in family, work, and law-abiding behavior

14-Item scale assessing perceived likelihood for achieving success in family, work, and low-abiding behavior

6-Item scale assessing perceived opportunities regarding schooling and work

A single scale summing the number of 8 domains for which at least one caring adult is present

A single scale measuring the extent of involvement in four different community organizations

3-Item scale assessing the extent of intergenerational closure in the community

5-Item scale assessing the extent of social integration in the community

5-Item scale assessing the perceived opportunity for work in the community

A single item measuring average yearly service attendance

A single item assessing the importance of subject's religion

7-Item scale measuring the perceived likelihood of detection and punishment for several types of offenses (subjects)

7-Item scale measuring the perceived likelihood of detection and punishment for several types of offenses (others)
"How much does your parent know about how you spend your free time?"

"How often do you have a set time to be home on weekend nights?"

"How often does your mother let you know she really cares about you?"

"How often does your mother get angry at you?

"How important it is to you to have a good family?"

"What do you think your chances are to earn a good living?"

"In my neighborhood, it is easy for young person to get good job"

"Adults you admire and want to be like"

e.g., sports teams, scouts, church related groups, and volunteer work

"How many of the parents of your friends know your parents?"

"How many of your teachers do your parents know by name?"

"Do employers around here often hire young people from this neighborhood?"

"How often did you attend church, synagogue, or other religious service"

"How important has religion been in your life?'

"How likely is it that in your neighborhood you would be caught and arrested for fighting?"

"How likely is it that kids in your neighborhood would be caught and arrested for fighting?" 
Table 1 (continued)

\begin{tabular}{|c|c|c|c|}
\hline Measure & Construction & Example Item & $\begin{array}{l}\alpha \text { (At the } \\
\text { baseline) }\end{array}$ \\
\hline Personal cost* & $\begin{array}{l}\text { 18-Item scale measuring } \\
\text { the personal cost of arrest }\end{array}$ & $\begin{array}{l}\text { "Has your court sentence kept } \\
\text { you from hanging out with your } \\
\text { friends as much as you used to?" }\end{array}$ & 0.93 \\
\hline Social cost* & $\begin{array}{l}\text { 6-Item scale measuring the } \\
\text { social cost of arrest }\end{array}$ & $\begin{array}{l}\text { "If the police catch me doing } \\
\text { something that breaks the law, } \\
\text { how likely is it that I would be } \\
\text { suspended from school" }\end{array}$ & 0.68 \\
\hline $\begin{array}{l}\text { Personal } \\
\text { reward* }\end{array}$ & $\begin{array}{l}\text { 7-Item scale measuring the } \\
\text { personal reward of crime }\end{array}$ & $\begin{array}{l}\text { "How much 'thrill' or 'rush' } \\
\text { is it to break into a store } \\
\text { or home?" }\end{array}$ & 0.88 \\
\hline \multicolumn{4}{|l|}{ Routine activities } \\
\hline $\begin{array}{l}\text { Unsupervised } \\
\text { socializing* }\end{array}$ & $\begin{array}{l}\text { 3-Item scale measuring the } \\
\text { frequency of unstructured } \\
\text { socializing in the absence } \\
\text { of authority figure }\end{array}$ & $\begin{array}{l}\text { "How often did you get together } \\
\text { with friends informally?" }\end{array}$ & 0.62 \\
\hline $\begin{array}{l}\text { Violence } \\
\text { victim* }\end{array}$ & $\begin{array}{l}\text { 6-Item scale measuring the } \\
\text { frequency of exposure to } \\
\text { violent events as a victim }\end{array}$ & $\begin{array}{l}\text { "Have you ever been chased } \\
\text { where you thought you might } \\
\text { be seriously hurt?" }\end{array}$ & 0.62 \\
\hline $\begin{array}{l}\text { Violence } \\
\text { witness* }\end{array}$ & $\begin{array}{l}\text { 7-Item scale measuring the } \\
\text { frequency of exposure to } \\
\text { violent events as a witness }\end{array}$ & $\begin{array}{l}\text { "Have you ever seen someone } \\
\text { else being raped, an attempt } \\
\text { made to rape someone or any } \\
\text { other type of sexual attack?" }\end{array}$ & 0.78 \\
\hline \multicolumn{4}{|c|}{ Psychological development } \\
\hline $\begin{array}{l}\text { PSMI (self- } \\
\quad \text { reliance)* }\end{array}$ & $\begin{array}{l}\text { 10-Item scale assessing the } \\
\text { subject's ability to make } \\
\text { decisions without extreme } \\
\text { reliance on others }\end{array}$ & $\begin{array}{l}\text { "Luck decides most things that } \\
\text { happen to me" }\end{array}$ & 0.75 \\
\hline PSMI (identity)* & $\begin{array}{l}\text { 10-Item scale assessing the } \\
\text { subject's self-esteem, clarity } \\
\text { of the self, and consideration } \\
\text { of life goals }\end{array}$ & $\begin{array}{l}\text { "I change the way I feel and act } \\
\text { so often that I sometimes } \\
\text { wonder who the 'real' me is" }\end{array}$ & 0.76 \\
\hline $\begin{array}{l}\text { PSMI (work } \\
\text { orientation)* }\end{array}$ & $\begin{array}{l}\text { 10-Item scale assessing the } \\
\text { subject's pride in the } \\
\text { successful completion } \\
\text { of tasks }\end{array}$ & $\begin{array}{l}\text { "I hate to admit it, but I give } \\
\text { up on my work when things } \\
\text { go wrong" }\end{array}$ & 0.74 \\
\hline Morality & $\begin{array}{l}\text { 32-Item scale assessing the } \\
\text { attitudes concerning the } \\
\text { treatment of others }\end{array}$ & $\begin{array}{l}\text { "It is alright to beat someone } \\
\text { who bad mouths your family" }\end{array}$ & 0.88 \\
\hline Anxiety & $\begin{array}{l}\text { 28-Item scale assessing the level } \\
\text { and nature of subject's anxiety }\end{array}$ & $\begin{array}{l}\text { e.g., physiological anxiety } \\
\text { (10 items), worry/oversensitivity } \\
\text { (11 items), and social concerns } \\
\text { (7 items) }\end{array}$ & 0.87 \\
\hline $\begin{array}{l}\text { Internal } \\
\text { emotionality }\end{array}$ & $\begin{array}{l}\text { 14-Item scale measuring subject's } \\
\text { internal emotionality }\end{array}$ & $\begin{array}{l}\text { "I am almost always calm-nothing } \\
\text { ever bothers me" }\end{array}$ & 0.67 \\
\hline Ethnic identity & $\begin{array}{l}\text { 12-Item scale assessing the feelings } \\
\text { of (1) affirmation and belonging } \\
\text { and (2) identity achievement }\end{array}$ & $\begin{array}{l}\text { "I am happy that I am a member } \\
\text { of the group I belong to" }\end{array}$ & N/A \\
\hline \multicolumn{4}{|l|}{ Low self-control } \\
\hline Temperance & $\begin{array}{l}\text { 15-Item scale measuring subject's } \\
\text { level of (1) impulse control } \\
\text { and (2) suppression of } \\
\text { aggression }\end{array}$ & $\begin{array}{l}\text { "I say the first thing that comes } \\
\text { into my mind without thinking } \\
\text { enough about it" }\end{array}$ & 0.84 \\
\hline Self-centeredness & $\begin{array}{l}\text { 7-Item scale measuring how the } \\
\text { subject considers others }\end{array}$ & $\begin{array}{l}\text { "Doing things to help other people } \\
\text { is more important to me than } \\
\text { almost anything else" }\end{array}$ & 0.73 \\
\hline
\end{tabular}


Table 1 (continued)

\begin{tabular}{|c|c|c|c|}
\hline Measure & Construction & Example Item & $\begin{array}{l}\alpha \text { (At the } \\
\text { baseline) }\end{array}$ \\
\hline Impulsivity & $\begin{array}{l}\text { 8-Item scale assessing the } \\
\text { degree of future consideration } \\
\text { and planning }\end{array}$ & $\begin{array}{l}\text { "I will keep working at difficult, } \\
\text { boring tasks if I know they } \\
\text { will help me get ahead later" }\end{array}$ & 0.71 \\
\hline \multicolumn{4}{|l|}{ Social learning } \\
\hline Peer behavior* & $\begin{array}{l}\text { 12-Item scale measuring the } \\
\text { prevalence of friends who } \\
\text { engage in antisocial behaviors }\end{array}$ & $\begin{array}{l}\text { "During the last six months how } \\
\text { many of your friends have } \\
\text { sold drugs?" }\end{array}$ & 0.92 \\
\hline Peer influence* & $\begin{array}{l}\text { 7-Item scale measuring the } \\
\text { prevalence of friends who } \\
\text { encourage antisocial behaviors }\end{array}$ & $\begin{array}{l}\text { "During the last six months how } \\
\text { many of your friends have } \\
\text { suggested that you should } \\
\text { sell drugs?" }\end{array}$ & 0.89 \\
\hline Peer resistance* & $\begin{array}{l}\text { 10-Item scale assessing the } \\
\text { ability to act autonomously } \\
\text { in interaction with peer group }\end{array}$ & $\begin{array}{l}\text { "Some people go along with } \\
\text { their friends just to keep their } \\
\text { friends happy" }\end{array}$ & 0.73 \\
\hline Gang involvement* & $\begin{array}{l}\text { A single item measuring } \\
\text { the level of the subject's } \\
\text { gang involvement }\end{array}$ & $\begin{array}{l}\text { "Have you been a member of } \\
\text { gang in the past } 6 \text { months?" }\end{array}$ & N/A \\
\hline Friends arrested & $\begin{array}{l}\text { A single item measuring the } \\
\text { number of closest friends } \\
\text { arrested }\end{array}$ & $\begin{array}{l}\text { "How many of your closest } \\
\text { friend have been arrest in } \\
\text { the past } 6 \text { months?" }\end{array}$ & $\mathrm{N} / \mathrm{A}$ \\
\hline
\end{tabular}

*Denotes that these measures were used as both control and mediating variables. The other measures were used solely as control variables because they were either theoretically irrelevant as mediators or available only at the baseline

\section{Mediating Variables ${ }^{5}$}

Several dimensions of mediating factors derived from Laub and Sampson [1]'s theory were used to further achieve the initial balance of the study groups and, more importantly, to investigate the causal mechanisms underlying the fatherhood effect on subsequent offending. Among others, stakes in conformity would increase as attachment to conventional others emerges and investment in social bonds grows after becoming a father. Although there was no direct measure of attachment to the mother or child, the current data had some indicators of commitment to achieving success in family, school, work, and law-abiding behavior (aspiration, expectation, and motivation for success) and stakes in conformity (personal cost, social cost, and personal reward of committing crime). Fatherhood can also change everyday routines and lifestyles, which are more immediate and proximate correlates of variation in crime and victimization (unsupervised/unstructured socializing, exposure to violent events as a victim or witness). In particular, taking the role of fathers and assuming parenting responsibility can cut off fathers from their antisocial peer network (peer behavior/influence/resistance and gang involvement). Lastly, fatherhood can change one's sense of self or identity (self-reliance, self-identity, work orientation). Table 1 also summarizes these proposed mediators.

\footnotetext{
${ }^{5}$ In order to establish temporal order, all the mediators were measured at the 12-month (adolescents) and 72month (young adults) follow-ups. At the same time, the same variables measured at the baseline (adolescents) and 60-month follow-up (young adults) were also included as covariates when estimating propensity scores and approximating a counterfactual group for the fatherhood transition group.
} 


\section{Analytic Strategy}

Ideally, a true randomized experimental design would minimize selection bias by creating two equivalent groups, but is not feasible in this study of fatherhood effects. Among alternative analytic strategies with observational data, PSM is often adopted to control for a range of observable confounders in non-experimental settings ([43]; see also [44, 45]). Although PSM might not be the best way to analyze the current data compared with alternative strategies (e.g., fixed/random effects models: [46, 47], growth curve/latent growth models: $[48,49])$ considering that it does not utilize all the individuals in the sample and multiple follow-up waves that are available, PSM is adopted for two reasons: First, while the alternative models could produce more robust findings by comparing the outcomes of the same individuals before and after becoming a father (and thus substantially reducing many time-invariant sources of selection bias), PSM can also provide a straightforward comparison of the outcomes between two similar groups of individuals who transition to fatherhood and who do not. In doing so, PSM can control for a variety of theoretically important variables no matter they are time-varying or time stable in nature. Second, while a conventional way of conducting outcome analyses after matching is successfully completed is to directly compare the between-group averages of outcomes using "psmatch2" [50] in STATA, there has been a few developments in PSM over the recent years that can not only improve the matching results (e.g., "optimal matching," "genetic matching": [51, 52]) but also produce "doubly robust" estimators of the average treatment effect on the treated (ATT) by adopting weighted multiple regression models on the matched data set using all the covariates included in the propensity score estimation $[52,53]$. The current study attempts to introduce one of these methods that are currently under-utilized in the field of criminology, which can be fully implemented using a statistical package readily available as free software.

The PSM analysis involves two major steps to increase the consistency and efficiency of the estimators: First, the data will be preprocessed using the MatchIt package for R [53] to achieve optimal covariate balance in which a vector of observed covariates and the fatherhood status are conditionally independent within matched sets. ${ }^{6}$ Second, parametric outcome analyses will be conducted by full regression models with the original covariates to estimate more accurate estimates of fatherhood effects by further controlling for any remaining bias that might exist even after matching is implemented. It is also known to be more robust to the model dependence in estimating treatment effects, which might vary depending upon different model specifications (e.g., choices of control variables, functional forms, modeling assumptions) [52].

After identifying the main effects of fatherhood using PSM and additional regression adjustments, "multiple mediator models" [54] within a SEM framework will be estimated to explore the causal mechanisms linking fatherhood to the changes in offending behavior. Initially, a series of similar PSM analyses, in which all the proposed mediators are treated as outcomes, will determine potential mediators of the association

\footnotetext{
${ }^{6}$ Operationally, "conditionally independent" means that even though a vector of observed covariates may strongly predict who will become a father, among individuals who have the same value of the propensity score, these observed covariates no longer predict who will enter into fatherhood. This assumption is known as "strong ignorability" [43].
} 
between fatherhood and offending. Then, both overall and specific mediation processes will be assessed using these mediators and subsequent offending measures. In doing so, inverse probability of treatment weights (IPTW) will be created and applied for treated and control cases separately, which accomplishes covariate balance in the multiple mediation model while retaining the original cases. Propensity score weighting with multiple mediation analysis can be performed as a conventional weighted SEM, which treats propensity score weights as sampling weights assuming that the data are generated by a complex sampling design. ${ }^{7}$ The only (conceptual) difference between propensity score weighting and survey weighting procedures is that the former assigns a different weighting to each case depending on the individual's conditional probability of receiving treatment conditions (see [55]: 239-254 for more detail).

\section{Results}

Considering that the current data involves serious male offenders who are predominantly disadvantaged minorities, the prevalence of parenthood transition is much higher than in the general population. ${ }^{8}$ Figure 1 shows that, while only $9 \%$ of the sample had a child during baseline interview (mean age 16.04), more than half of the subjects became parents by the 84-month follow-up (mean age 23.04). Although this study compares the consequences of fatherhood transition among adolescents (mean age at the baseline 15.88, range 14-19) and young adults (mean age at the 60-month followup 20.85, range 19-23), targeting these fairly young samples is still desirable considering that the normative timing of transition into parenthood is much earlier in these groups than it is in the general US population. ${ }^{9}$

\section{The Consequences of Becoming a Father: During Adolescence}

In order to establish temporal order, this study compares self-reported offending at 12and 24-month follow-ups between the adolescents who had their first child and those who did not during the first year of the study. ${ }^{10}$ Before matching, the teen fathers reported a significantly higher level of offending than their counterparts at both 12month (frequency 95.44 vs. $26.82, p<0.01$; variety 0.11 vs. $0.07, p<0.01$ ) and 24 month (frequency 138.06 vs. $50.78, p<0.01$; variety 0.11 vs. $0.06, p<0.01$ ) followups. As presented in Table 2, however, the two groups were different in some significant ways even before the change of fatherhood status occurred, which makes it plausible to assume that becoming a teen father might not be a random event, but

\footnotetext{
${ }^{7}$ For estimating ATT, IPTW estimators are calculated by (1) [the probability of treatment/(1 - the probability of treatment)] for each control case and (2) simply assigning 1 for each treatment case.

${ }^{8}$ In 2012, there were 29.4 and 83.1 births for every 1000 adolescent (aged 15-19) and young adult (aged 2024) women, respectively [56].

9 The average age of mother at first birth continues to rise in the general population with 25.8 in 2012 [57].

${ }^{10}$ Considering that more than a few non-fathers during the first year ( $0-12$ months) became fathers during the second year (12-24 months), which might attenuate the otherwise salient impact of fatherhood transition, the current study excluded a subset of sample who changed fatherhood status during the second year of the study $(n=93)$ to better examine the long-term effect of the fatherhood transition. Nonetheless, substantive findings were almost identical when either sample was used (available upon request).
} 


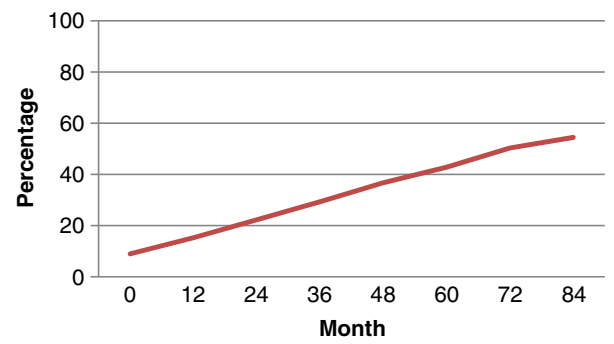

Fig. 1 Percentage of parent during baseline and follow-up interviews

rather an outcome of the early risk factors that adolescents had been accumulating in multiple domains of life. In particular, consistent with the national patterns [56], the teen father group on average was significantly older (mean age 16.44 vs. 15.86) and had a lower percentage of White $(0.08$ vs. 0.23$)$ than the non-father group. While the frequency of self-reported offending was not significantly different between the two groups at the baseline (but it was considerably higher for the father group: $224.41 \mathrm{vs.}$ 142.36), the teen fathers still reported more prior petitions to court (3.86 vs. 3.04) than non-fathers even before they had their first child. More noticeably, the father group manifested different patterns in their romantic relationships and previous sexual activities, all of which are known to be the strongest predictors for teen pregnancy and childbirth [58]. For example, the teen fathers reported a significantly higher number of sexual partners (13.91 vs. 9.11) and a longer period of romantic relationship (4.83 vs. $4.10 p<0.01)$ and were more likely to have been deeply in love $(0.73$ vs. 0.39$)$ than their counterparts. Teen fathers also reported a lower level of informal social control from their own parents (e.g., parental monitoring 2.56 vs. 2.76; parental knowledge 2.55 vs. 2.84) and perceived risk of punishment for themselves ( 4.39 vs. 5.23), a higher level of association with delinquent peers (2.72 vs. 2.30), and exposure to violence as victims (4.23 vs. 3.69$)$.

To explore the impact of fatherhood on offending and other proposed mediating variables, a set of similar PSM models were estimated in which the adolescents who did not report any children at the baseline interview but had a first child before the 12month follow-up $(n=64)$ were compared with their counterparts who manifested a similar propensity to becoming a father but did not enter into fatherhood $(n=800)$. The propensity scores for becoming a father given the 59 observed covariates were estimated for each individual using a logistic regression model. ${ }^{11}$ Despite the evidence indicating a lack of balance between the two groups, the distributions of propensity

\footnotetext{
${ }^{11}$ The full logistic regression model and its results are available upon request. Since the goal of propensity score estimation is to achieve balance on the measured covariates, it is better to include as many relevant variables as possible rather than too few variables in the name of parsimony. While there are some occasions in which over-parameterization of the model is not recommended in the PSM analysis (e.g., when it exacerbates the lack of common support problem and increases the variance of the estimators, especially when many treated units have to be discarded from the analysis or control units have to be used more than once due to a lack of common support: [59]), the current data show substantial overlap in the distributions of propensity scores conditional on fatherhood status even after 59 relevant covariates were included in the matching procedure. Rubin \& Thomas [60] also recommended that variables should not be excluded from the model for the interest of parsimony if there are theoretical and empirical rationales to include them in the propensity score estimation.
} 
scores conditional on fatherhood status showed substantial overlap with 62 out of 64 cases in the father group falling within the range of the control distribution. ${ }^{12}$ Accordingly, it was possible to find reasonably good matches for each treatment case in the control group even for the individuals with extremely large propensity scores. ${ }^{13}$

There are a number of matching methods for selecting non-fathers who closely resemble fathers in terms of the estimated propensity scores ${ }^{14}$ (e.g., nearest neighbor, full, exact, coarsened exact, radius, kernel, optimal matching: see [55]: 145-152; [44]: 551-552 for more detail). Given the lack of specific guidance in the literature on which of these matching options works best under which condition, this study first compared the results from all of these matching methods to check the robustness of substantive findings [62]. The magnitude and significance level of the fatherhood effects from different matching procedures were almost identical, and hence the bias-variance tradeoff was not a big concern (available upon request). Considering that "full matching" achieved the optimal balance of covariates across all individuals while retaining most of the cases in the original sample, ${ }^{15}$ the following sections present the results from the full matching with "variable matches" (which does not require every treatment to have the same number of controls but allows treatment subjects to pair only with the good matches in the control subjects) in the interest of parsimony.

Before discussing the PSM results, matching quality should be checked to assess the tenability of the conditional independence assumption. The literature suggests some statistical and graphical balance diagnostics for comparing the distribution of covariates. The widely adopted procedure of conducting statistical significance test of group mean differences after matching (e.g., $t$ test) is discouraged because the covariate balance achieved through matching is merely a characteristic of the observed sample ("balance test fallacy": [63]) and is sensitive to sample size [64, 65]. Table 2 shows that, while the bias diagnostics before matching suggested a substantial amount of preexisting differences between the two groups, full matching reduced them substantially with no differences remaining more than a quarter of a standard deviation of the respective covariate in the original treatment group [66]. MatchIt also produced a variety of diagnostic plots (e.g., effect size plot/jitter plot/histogram of propensity scores and Q-Q plots of each covariate), which also suggested that empirical distributions of the estimated propensity scores and each covariate were similar in the treated and control groups after matching (available upon request).

\footnotetext{
12 The ranges of the estimated propensity scores for father and non-father groups were .007 to .832 and .000 to .613 respectively. Only two case in the father group with extremely large propensity scores $(.742$ and .832$)$ fell outside the range of the control distribution.

${ }^{13}$ Dehejia and Wahba [61] maintain that most of matching methods produce substantively similar results when there is substantial overlap in the distributions of the propensity scores between the two study groups.

${ }^{14}$ Since cases are matched by the propensity scores estimated based on all covariates instead of each individual covariate score, the distributions of covariates for both groups (not individual covariate scores for each matched pair) should be similar after matching. Nonetheless, the benefits of matching on all covariates individually are also attainable [43].

${ }^{15}$ Considering that the current study employs weighted full regression models with the original 59 covariates when estimating treatment effects after the matching procedure, and many matching methods (especially, those resting on one-to-one or one-to-few matching algorithms) retain only a small number of matched pairs, full matching is preferred in this study to maintain enough sample size for the subsequent multivariate outcome analyses.
} 
Table 2 Assessment of covariate balance before and after matching (adolescents)

\begin{tabular}{|c|c|c|c|c|c|c|c|c|}
\hline \multirow[t]{3}{*}{ Variables } & \multicolumn{4}{|c|}{ Unmatched } & \multicolumn{4}{|l|}{ Matched } \\
\hline & Father & $\begin{array}{l}\text { Non- } \\
\text { father }\end{array}$ & Mean & Std. mean & Father & $\begin{array}{l}\text { Non- } \\
\text { father }\end{array}$ & Mean & Std. Mean \\
\hline & $(n=64)$ & $(n=800)$ & Diff. & Diff. & $(n=64)$ & $(n=800)$ & Diff. & Diff. \\
\hline Propensity score & 0.22 & 0.06 & 0.16 & 0.88 & 0.22 & 0.22 & 0.01 & 0.03 \\
\hline \multicolumn{9}{|l|}{ Demographic characteristics } \\
\hline Age & 16.44 & 15.86 & 0.58 & 0.66 & 16.44 & 16.42 & 0.02 & 0.02 \\
\hline White & 0.08 & 0.23 & -0.15 & -0.57 & 0.08 & 0.08 & 0.00 & -0.02 \\
\hline Black & 0.42 & 0.40 & 0.02 & 0.05 & 0.42 & 0.45 & -0.03 & -0.05 \\
\hline Hispanic & 0.44 & 0.33 & 0.11 & 0.22 & 0.44 & 0.44 & 0.00 & 0.00 \\
\hline IQ score & 83.47 & 85.21 & -1.74 & -0.14 & 83.47 & 85.16 & -1.69 & -0.14 \\
\hline No. of bio parents & 1.09 & 1.00 & 0.09 & 0.17 & 1.09 & 1.10 & 0.00 & 0.00 \\
\hline No adults & 0.05 & 0.03 & 0.01 & 0.06 & 0.05 & 0.04 & 0.00 & 0.02 \\
\hline Parent education & 4.40 & 4.27 & 0.13 & 0.14 & 4.40 & 4.40 & 0.00 & 0.00 \\
\hline Parent social position & 50.67 & 51.32 & -0.65 & -0.05 & 50.67 & 51.27 & -0.60 & -0.05 \\
\hline Family arrested & 0.80 & 0.78 & 0.02 & 0.05 & 0.80 & 0.80 & 0.00 & -0.01 \\
\hline Employed & 0.20 & 0.26 & -0.06 & -0.15 & 0.20 & 0.20 & 0.01 & 0.02 \\
\hline \multicolumn{9}{|l|}{ Early problem behaviors } \\
\hline No. of prior offending & 224.41 & 142.36 & 82.04 & 0.19 & 224.41 & 238.67 & -14.26 & -0.03 \\
\hline No. of petitions & 3.86 & 3.04 & 0.82 & 0.33 & 3.86 & 3.90 & -0.04 & -0.02 \\
\hline Age of first petition & 15.11 & 14.87 & 0.24 & 0.14 & 15.11 & 15.07 & 0.04 & 0.02 \\
\hline No. of sexual partners & 13.91 & 9.11 & 4.79 & 0.26 & 13.91 & 15.48 & -1.57 & -0.09 \\
\hline Age of first sex & 13.11 & 13.02 & 0.09 & 0.04 & 13.11 & 12.94 & 0.17 & 0.09 \\
\hline No. of one-night stands & 6.70 & 4.56 & 2.15 & 0.18 & 6.70 & 7.14 & -0.44 & -0.04 \\
\hline Multiple sexual relationship & 0.52 & 0.44 & 0.07 & 0.14 & 0.52 & 0.51 & 0.00 & 0.00 \\
\hline Unfaithful to partner & 0.73 & 0.63 & 0.10 & 0.23 & 0.73 & 0.75 & -0.01 & -0.03 \\
\hline Duration of romantic relationship & 4.83 & 4.10 & 0.73 & 0.62 & 4.83 & 4.81 & 0.02 & 0.01 \\
\hline Ever deeply in love & 0.73 & 0.39 & 0.34 & 0.76 & 0.73 & 0.71 & 0.02 & 0.05 \\
\hline \multicolumn{9}{|l|}{ Social control/bond } \\
\hline Parental knowledge & 2.56 & 2.76 & -0.20 & -0.26 & 2.56 & 2.55 & 0.01 & 0.01 \\
\hline Parental monitoring & 2.55 & 2.84 & -0.29 & -0.32 & 2.55 & 2.50 & 0.04 & 0.05 \\
\hline Maternal warmth & 3.23 & 3.23 & 0.00 & 0.00 & 3.23 & 3.20 & 0.03 & 0.05 \\
\hline Maternal hostility & 1.65 & 1.57 & 0.08 & 0.18 & 1.65 & 1.63 & 0.02 & 0.05 \\
\hline Aspiration for success & 4.36 & 4.42 & -0.06 & -0.11 & 4.36 & 4.35 & 0.00 & 0.00 \\
\hline Expectation for success & 3.34 & 3.42 & -0.08 & -0.09 & 3.34 & 3.32 & 0.02 & 0.02 \\
\hline Motivation to succeed & 3.25 & 3.27 & -0.03 & -0.05 & 3.25 & 3.37 & -0.12 & -0.20 \\
\hline Social support (diversity) & 4.16 & 4.08 & 0.08 & 0.04 & 4.16 & 4.26 & -0.11 & -0.06 \\
\hline Community involvement & 0.70 & 0.67 & 0.03 & 0.04 & 0.70 & 0.68 & 0.02 & 0.02 \\
\hline Social capital (cohesion) & 2.55 & 2.49 & 0.06 & 0.11 & 2.55 & 2.53 & 0.02 & 0.04 \\
\hline Social capital (integration) & 2.20 & 2.16 & 0.03 & 0.06 & 2.20 & 2.17 & 0.03 & 0.05 \\
\hline Social capital (opportunity) & 3.46 & 3.46 & 0.00 & 0.01 & 3.46 & 3.54 & -0.08 & -0.13 \\
\hline Religion frequency & 2.22 & 2.27 & -0.05 & -0.04 & 2.22 & 2.31 & -0.09 & -0.07 \\
\hline Religion importance & 3.13 & 3.23 & -0.10 & -0.08 & 3.13 & 3.14 & -0.01 & -0.01 \\
\hline \multicolumn{9}{|l|}{ Low self-control } \\
\hline Temperance & 2.92 & 2.86 & 0.06 & 0.07 & 2.92 & 2.92 & 0.00 & 0.00 \\
\hline Self-centeredness & 3.47 & 3.43 & 0.04 & 0.04 & 3.47 & 3.46 & 0.01 & 0.01 \\
\hline Impulsivity & 2.40 & 2.31 & 0.09 & 0.17 & 2.40 & 2.42 & -0.02 & -0.05 \\
\hline
\end{tabular}


Table 2 (continued)

\begin{tabular}{|c|c|c|c|c|c|c|c|c|}
\hline \multirow[t]{3}{*}{ Variables } & \multicolumn{4}{|c|}{ Unmatched } & \multicolumn{4}{|l|}{ Matched } \\
\hline & Father & $\begin{array}{l}\text { Non- } \\
\text { father }\end{array}$ & Mean & Std. mean & Father & $\begin{array}{l}\text { Non- } \\
\text { father }\end{array}$ & Mean & Std. Mean \\
\hline & $(n=64)$ & $(n=800)$ & Diff. & Diff. & $(n=64)$ & $(n=800)$ & Diff. & Diff. \\
\hline \multicolumn{9}{|l|}{ Social learning } \\
\hline Peer behavior & 2.72 & 2.30 & 0.41 & 0.50 & 2.72 & 2.76 & -0.04 & -0.05 \\
\hline Peer influence & 1.87 & 1.78 & 0.09 & 0.12 & 1.87 & 1.86 & 0.01 & 0.02 \\
\hline Peer resistance & 2.98 & 2.93 & 0.05 & 0.09 & 2.98 & 3.01 & -0.03 & -0.05 \\
\hline Gang involvement & 0.31 & 0.23 & 0.08 & 0.17 & 0.31 & 0.31 & 0.01 & 0.01 \\
\hline Friends arrested & 0.51 & 0.44 & 0.06 & 0.18 & 0.51 & 0.52 & -0.01 & -0.03 \\
\hline \multicolumn{9}{|l|}{ Routine activities } \\
\hline Unsupervised socializing & 3.91 & 3.85 & 0.07 & 0.08 & 3.91 & 3.89 & 0.03 & 0.03 \\
\hline Violence victim & 4.23 & 3.69 & 0.55 & 0.30 & 4.23 & 4.37 & -0.14 & -0.07 \\
\hline Violence witness & 1.81 & 1.57 & 0.24 & 0.19 & 1.81 & 1.86 & -0.05 & -0.04 \\
\hline \multicolumn{9}{|l|}{ Rational choice } \\
\hline Certainty (you) & 4.39 & 5.28 & -0.89 & -0.33 & 4.39 & 4.49 & -0.10 & -0.04 \\
\hline Certainty (others) & 5.03 & 5.53 & -0.49 & -0.22 & 5.03 & 4.84 & 0.19 & 0.09 \\
\hline Personal cost & 9.36 & 9.56 & -0.20 & -0.03 & 9.36 & 9.10 & 0.26 & 0.04 \\
\hline Social cost & 2.72 & 2.77 & -0.05 & -0.07 & 2.72 & 2.74 & -0.03 & -0.04 \\
\hline Personal reward & 2.63 & 2.44 & 0.18 & 0.08 & 2.63 & 2.62 & 0.01 & 0.01 \\
\hline \multicolumn{9}{|l|}{ Psychological development } \\
\hline PSMI (self-reliance) & 3.05 & 3.10 & -0.05 & -0.11 & 3.05 & 3.11 & -0.06 & -0.12 \\
\hline PSMI (identity) & 3.14 & 3.22 & -0.07 & -0.15 & 3.14 & 3.15 & -0.01 & -0.01 \\
\hline PSMI (work orientation) & 2.77 & 2.75 & 0.01 & 0.03 & 2.77 & 2.77 & 0.00 & -0.01 \\
\hline Morality & 1.65 & 1.62 & 0.03 & 0.09 & 1.65 & 1.66 & -0.01 & -0.02 \\
\hline Anxiety & 10.06 & 9.61 & 0.45 & 0.07 & 10.06 & 9.77 & 0.29 & 0.04 \\
\hline Internal emotionality & 2.65 & 2.66 & -0.01 & -0.02 & 2.65 & 2.63 & 0.01 & 0.02 \\
\hline Ethnic identity & 2.81 & 2.76 & 0.05 & 0.11 & 2.81 & 2.82 & -0.01 & -0.02 \\
\hline
\end{tabular}

While even stricter cutoffs are also used to assess the balance of the measured covariates (e.g., 0.10), the current study assumes that a covariate is balanced if the standardized mean difference is less than 0.25 [52]. Considering that it is merely a rule of thumb, not an absolute criterion, however, a holistic approach is needed to assess the overall quality of the covariate balance (e.g., compare the average differences between groups after carefully considering the covariates with a standardized difference of slightly lower than 0.25 )

Outcome analyses were conducted by weighted multiple regression models on the matched data set using all the covariates included in the propensity score estimation to control for the remaining covariate imbalance after matching. It is known to produce "doubly robust" estimators of ATT ([52]: 215) regardless of the matching methods employed [67, 68]. Since full matching produces variable numbers of treated and control cases within matched subsets, the weights created by MatchIt were used in estimating ATT to ensure the comparability of the matched treated and control cases. Table 4 shows that the fatherhood transition during adolescence leads to an increase in both current and future offending behaviors regardless of the type of offending measures used. Most of the adverse effects of the fatherhood transition remained significant even after doubly adjusting for the initial differences through propensity score matching and multiple regression adjustment. At the same time, while becoming 
a teen father significantly reduced unsupervised socializing with peers $(-.18, p<0.05)$, it increased exposure to violence as a victim or witness $(.78, p<0.001)$, association with antisocial peers $(.23, p<0.01)$, and influence of those peers $(.17, p<0.05)$. Thus, it is obvious that in the current sample there is a crime-generating effect of becoming a teen father, which is known to be one of the primary negative consequences of teen pregnancy/parenthood in a more general population (e.g., $[58,69]) .{ }^{16}$ At the same time, these results are contradictory to the crime-inhibiting effects of teen parenthood often documented in a body of literature, especially when disadvantaged minority samples and/or female samples were used (e.g., $[15,19])$. The results are also inconsistent with the claim that early transition into parenthood functions as a turning point for criminal desistance through the same mechanisms as other well-researched turning points in life (e.g., [32-35]) because, in the current data, too early of a transition to the adult role of fatherhood did not trigger or speed up the mechanisms of the criminal desistance. Precociously assuming a father's role among these adjudicated offenders rather increased dangerous lifestyles and delinquent peer association and its influence presumably because teen fathers were not developmentally ready to deal with the difficulties and stresses associated with the parenting roles and lack the ability to support their romantic partners and children through legitimate channels [71]. More detailed and nuanced relationship contingencies could not be examined because further information about the nature and quality of relationship between fathers and romantic partners or their children was not available. In sum, early childbirth appears to be either one of the symptoms of early risk factors predicting both premature childbirth and offending, or even a facilitating factor for the subsequent offending by exposing teen fathers to the circumstances and relationship contexts where crime is more likely.

\section{The Consequences of Becoming a Father: During Early Adulthood}

To explore whether the transition into fatherhood during early adulthood has different consequences to male offenders' lives, a similar set of PSM analyses were repeated by comparing the young adults who had their first child between the 60- and 72-month follow-ups $(n=69)$ with their counterparts who did not report any child during this period $(n=407)$. While some patterns of the preexisting differences observed in the adolescent sample continued to exist, Table 3 shows that there were considerably less covariate imbalances even before matching was implemented than in the adolescent sample. Nonetheless, young adult fathers were more likely to be employed (21.26 vs.16.26) and married (0.09 vs. 0.02) than non-fathers which are often conceived as major transitions to adulthood in the criminal desistance literature, omission of which would essentially exaggerate the fatherhood effects observed. The distributions of

\footnotetext{
${ }^{16}$ For example, teenage mothers are less likely to complete school and go to college, more likely to have large families, be single, and abuse their children. The children of teenage mothers are more likely to have lower school achievement and drop out of high school, have more health problems, be incarcerated at some time during adolescence, give birth as a teenager, and face unemployment as a young adult [70]. In 2008, teen pregnancy and childbirth cost the USA nearly $\$ 11$ billion through immediate and long-term impacts on teen parents and their children such as increased health care and foster care, increased incarceration rates among children of teen parents, and lost tax revenue because of lower educational attainment and income among teen mothers (http://www.thenationalcampaign.org/costs/default.aspx).
} 
propensity scores conditional on the fatherhood status also suggested substantial overlap with none of the cases in the father group failing to find a good match in the control group. Table 3 and other diagnostic plots (not shown, available upon request) suggested that, after employing the full matching method, none of the preexisting differences initially observed were of serious concern. Contrary to the results from the adolescent sample, however, Table 4 shows that young adult fathers reported consistently lower levels of different types of offending behaviors after having a first child than non-fathers even after PSM and additional regression adjustment were employed in the outcome analysis. Although none of these estimated ATTs were statistically significant by conventional criteria, these results were consistent with the patterns observed in a growing body of qualitative (e.g., [1, 19, 20]) and quantitative (e.g., [15]) research from a variety of disciplines, which documented beneficial effects of parenthood transition especially among disadvantaged minority groups. The relatively weak and non-significant effects observed might result from the youthfulness of the young adult fathers who were still in their early 20 s, during which period childbearing tends to be an unintended outcome in the absence of good and stable relationship contexts with partners $[31,72]$. After all, it was noticeable that the observed differences in the outcomes could not be fully ascribed to other salient adulthood transitions such as employment and marriage because the ATTs were estimated after adjusting those differences.

While the current study failed to find a convincing empirical support for the crime inhibiting effects of fatherhood transition during early adulthood, fatherhood still had significant impacts on a variety of mediating factors as expected from the theory: increased aspiration $(.12, p<0.05)$ and expectation $(.24, p<0.01)$ for success, reduced unstructured socializing with peers $(-0.27, p<0.01)$ and exposure to violence $(-0.54$, $p<0.01)$, and increased self-esteem, clarity of self, and consideration of life goals $(0.05$, $p<0.05$ ). These mediators represent key dimensions of the causal mechanism underlying turning point effects proposed by Laub and Sampson [1].

\section{The Causal Link Between Fatherhood and Offending}

Multiple mediation analysis [54] demonstrates that the predictions derived from Laub and Sampson [1]'s revised life-course theory are partially supported in the current data. While several statistical packages are available, Mplus (version 7.11, [74]) is useful in estimating total and specific indirect effects because of its flexibility in creating many types of bootstrap confidence intervals (CIs) such as percentile, bias-corrected, or bias corrected and accelerated CIs for any parameters of interest ([54]: 885). ${ }^{17}$ Figure 2 shows the total, direct, and indirect effects of fatherhood transition on subsequent offending among adolescents after adjusting covariate imbalances by propensity score weighting with IPTW and additionally controlling for the time spent in facilities

\footnotetext{
${ }^{17}$ Considering that the distribution of an indirect effect estimator is not necessarily normal or even symmetrical but usually positively skewed [73], conventional statistical test of mediation under the assumption of the standard normal distribution of the estimated standard error tends to be underpowered ([54]: 720-22). To address this issue, it is recommended that confidence intervals of the indirect effect estimators be created empirically using bootstrapping procedures, a nonparametric resampling approach that makes no assumption about normality.
} 
Table 3 Assessment of covariate balance before and after matching (young adults)

\begin{tabular}{|c|c|c|c|c|c|c|c|c|}
\hline \multirow[t]{3}{*}{ Variables } & \multicolumn{4}{|c|}{ Unmatched } & \multicolumn{4}{|l|}{ Matched } \\
\hline & Father & $\begin{array}{l}\text { Non- } \\
\text { father }\end{array}$ & Mean & Std. mean & Father & $\begin{array}{l}\text { Non- } \\
\text { father }\end{array}$ & Mean & Std. mean \\
\hline & $(n=69)$ & $(n=407)$ & Diff. & Diff. & $(n=69)$ & $(n=407)$ & Diff. & Diff. \\
\hline Propensity score & 0.29 & 0.12 & 0.17 & 0.87 & 0.29 & 0.29 & 0.00 & 0.00 \\
\hline \multicolumn{9}{|l|}{ Demographic characteristics } \\
\hline Age* & 20.67 & 20.90 & -0.24 & -0.21 & 20.67 & 20.65 & 0.02 & 0.02 \\
\hline White & 0.16 & 0.29 & -0.13 & -0.36 & 0.16 & 0.16 & 0.00 & 0.00 \\
\hline Black & 0.51 & 0.31 & 0.20 & 0.39 & 0.51 & 0.55 & -0.04 & -0.08 \\
\hline Hispanic & 0.33 & 0.35 & -0.01 & -0.03 & 0.33 & 0.29 & 0.04 & 0.10 \\
\hline IQ score & 84.28 & 86.36 & -2.08 & -0.16 & 84.28 & 82.74 & 1.54 & 0.12 \\
\hline No. of bio parents & 0.94 & 1.00 & -0.06 & -0.10 & 0.94 & 0.92 & 0.02 & 0.04 \\
\hline No adults & 0.04 & 0.04 & 0.00 & 0.00 & 0.04 & 0.03 & 0.01 & 0.05 \\
\hline Parent education & 4.36 & 4.23 & 0.13 & 0.16 & 4.36 & 4.34 & 0.02 & 0.03 \\
\hline Parent social position & 53.12 & 51.24 & 1.88 & 0.16 & 53.12 & 52.76 & 0.36 & 0.03 \\
\hline Family arrested & 0.86 & 0.79 & 0.06 & 0.18 & 0.86 & 0.88 & -0.02 & -0.08 \\
\hline Employed* & 21.26 & 16.26 & 5.00 & 0.26 & 21.26 & 21.51 & -0.25 & -0.01 \\
\hline Married* & 0.09 & 0.02 & 0.07 & 0.25 & 0.09 & 0.06 & 0.03 & 0.09 \\
\hline \multicolumn{9}{|l|}{ Early problem behaviors } \\
\hline No. of prior offending* & 57.55 & 73.19 & -15.64 & -0.07 & 57.55 & 91.54 & -33.99 & -0.16 \\
\hline No. of petitions & 2.74 & 3.10 & -0.36 & -0.18 & 2.74 & 2.64 & 0.10 & 0.05 \\
\hline Age at first petition & 15.03 & 14.86 & 0.17 & 0.11 & 15.03 & 15.07 & -0.04 & -0.03 \\
\hline No. of sexual partners & 10.93 & 8.18 & 2.75 & 0.18 & 10.93 & 12.24 & -1.27 & -0.09 \\
\hline Age of first sex & 12.73 & 13.18 & -0.45 & -0.26 & 12.73 & 12.83 & -0.10 & -0.06 \\
\hline No. of one-night stand & 4.61 & 4.10 & 0.51 & 0.05 & 4.61 & 5.85 & -1.24 & -0.12 \\
\hline Multiple sexual relationship & 0.47 & 0.40 & 0.07 & 0.14 & 0.47 & 0.50 & -0.03 & -0.06 \\
\hline Unfaithful to partner & 0.69 & 0.61 & 0.08 & 0.18 & 0.69 & 0.71 & -0.02 & -0.04 \\
\hline Period of romantic relationship & 4.17 & 3.95 & 0.23 & 0.16 & 4.17 & 4.40 & -0.23 & -0.16 \\
\hline Ever deeply in love & 0.38 & 0.37 & 0.01 & 0.02 & 0.38 & 0.36 & 0.02 & 0.03 \\
\hline \multicolumn{9}{|l|}{ Social control/bond } \\
\hline Aspiration for success* & 4.54 & 4.53 & 0.01 & 0.02 & 4.54 & 4.51 & 0.03 & 0.05 \\
\hline Expectation for success* & 3.74 & 3.75 & 0.00 & 0.00 & 3.74 & 3.78 & -0.04 & -0.04 \\
\hline Motivation to succeed* & 3.47 & 3.49 & -0.02 & -0.04 & 3.47 & 3.50 & -0.03 & -0.06 \\
\hline Social support (diversity)* & 1.65 & 1.53 & 0.13 & 0.11 & 1.65 & 1.76 & -0.11 & -0.09 \\
\hline Social capital (cohesion)* & 2.47 & 2.45 & 0.02 & 0.05 & 2.47 & 2.47 & 0.00 & 0.00 \\
\hline Social capital (integration)* & 2.18 & 2.13 & 0.05 & 0.11 & 2.18 & 2.19 & -0.01 & -0.02 \\
\hline Social capital (opportunity)* & 3.36 & 3.42 & -0.06 & -0.10 & 3.36 & 3.36 & 0.00 & 0.00 \\
\hline Religion frequency* & 2.41 & 2.29 & 0.12 & 0.09 & 2.41 & 2.41 & 0.00 & 0.00 \\
\hline Religion importance* & 3.44 & 3.20 & 0.24 & 0.18 & 3.44 & 3.43 & 0.01 & 0.03 \\
\hline \multicolumn{9}{|l|}{ Low self-control } \\
\hline Temperance* & 3.24 & 3.14 & 0.10 & 0.13 & 3.24 & 3.22 & 0.02 & 0.03 \\
\hline Self-centeredness* & 3.71 & 3.76 & -0.05 & -0.07 & 3.71 & 3.88 & -0.17 & -0.23 \\
\hline Impulsivity* & 2.72 & 2.65 & 0.07 & 0.13 & 2.72 & 2.70 & 0.02 & 0.05 \\
\hline \multicolumn{9}{|l|}{ Social learning } \\
\hline Peer behavior* & 1.64 & 1.76 & -0.12 & -0.15 & 1.64 & 1.66 & -0.02 & -0.03 \\
\hline Peer influence* & 1.41 & 1.53 & -0.12 & -0.17 & 1.41 & 1.40 & 0.01 & 0.01 \\
\hline Peer resistance* & 3.44 & 3.33 & 0.10 & 0.23 & 3.44 & 3.47 & -0.03 & -0.07 \\
\hline Gang involvement* & 0.31 & 0.24 & 0.07 & 0.15 & 0.31 & 0.32 & -0.01 & -0.02 \\
\hline
\end{tabular}


Table 3 (continued)

\begin{tabular}{|c|c|c|c|c|c|c|c|c|}
\hline \multirow[t]{3}{*}{ Variables } & \multicolumn{4}{|c|}{ Unmatched } & \multicolumn{4}{|l|}{ Matched } \\
\hline & Father & $\begin{array}{l}\text { Non- } \\
\text { father }\end{array}$ & Mean & Std. mean & Father & $\begin{array}{l}\text { Non- } \\
\text { father }\end{array}$ & Mean & Std. mean \\
\hline & $(n=69)$ & $(n=407)$ & Diff. & Diff. & $(n=69)$ & $(n=407)$ & Diff. & Diff. \\
\hline \multicolumn{9}{|l|}{ Routine activities } \\
\hline Unsupervised socializing* & 2.95 & 3.05 & -0.11 & -0.11 & 2.95 & 2.99 & -0.04 & -0.05 \\
\hline Violence victim* & 0.94 & 1.00 & -0.06 & -0.03 & 0.94 & 1.13 & -0.19 & -0.02 \\
\hline Violence witness* & 0.28 & 0.21 & 0.06 & 0.09 & 0.28 & 0.29 & -0.01 & -0.04 \\
\hline \multicolumn{9}{|l|}{ Rational choice } \\
\hline Certainty (you)* & 5.78 & 5.58 & 0.20 & 0.07 & 5.78 & 5.89 & -0.11 & 0.08 \\
\hline Certainty (others)* & 5.31 & 5.54 & -0.24 & -0.11 & 5.31 & 5.55 & -0.24 & -0.11 \\
\hline Social cost* & 3.38 & 3.30 & 0.07 & 0.08 & 3.38 & 3.25 & 0.13 & 0.14 \\
\hline Personal reward* & 1.49 & 1.77 & -0.28 & -0.12 & 1.49 & 1.43 & 0.06 & 0.02 \\
\hline \multicolumn{9}{|l|}{ Psychological development } \\
\hline PSMI (self-reliance)* & 3.38 & 3.32 & 0.07 & 0.13 & 3.38 & 3.38 & 0.00 & 0.00 \\
\hline PSMI (identity)* & 3.42 & 3.38 & 0.04 & 0.09 & 3.42 & 3.46 & -0.04 & -0.09 \\
\hline PSMI (work orientation)* & 3.16 & 3.06 & 0.10 & 0.24 & 3.16 & 3.18 & -0.02 & -0.04 \\
\hline Morality* & 1.37 & 1.46 & -0.09 & -0.27 & 1.37 & 1.34 & 0.03 & 0.08 \\
\hline Anxiety & 8.88 & 10.24 & -1.36 & -0.23 & 8.88 & 9.02 & -0.14 & -0.02 \\
\hline Internal emotionality & 2.67 & 2.70 & -0.02 & -0.04 & 2.67 & 2.72 & -0.05 & -0.08 \\
\hline
\end{tabular}

*Denotes that these variables are updated to the most recent before-treatment time frame (60-month follow-up) because the covariates may change significantly over time and the outdated info would fail to capture the real differences observed closely before the treatment occurs

without access to community. ${ }^{18}$ Considering that two of the potential mediators identified in the PSM analyses (unsupervised socializing and peer influence) failed to significantly predict the outcome, which is one of the necessary conditions for mediation to occur [54], only the two remaining mediators were included in the final mediation analysis.

Consistent with the PSM results, the total effect of teen fatherhood on subsequent offending $(.048, p<0.001)$ and the direct effects of fatherhood transition on exposure to violence $(0.742, p<0.001)$ and association with antisocial peers $(.199, p<0.001)$ were statistically significant. At the same time, the direct effects of the proposed mediators on subsequent offending after controlling for the other covariates were also significant (exposure to violence $0.022, p<0.001$; association with antisocial peer 0.045 , $p<0.001)$. When these mediators were considered simultaneously in the model, the direct effect of fatherhood on offending $(.048, p<0.001)$ was reduced substantially but still remained statistically significant $(.022, p<0.01)$, suggesting that it was partially mediated by the mediators. Not surprisingly, the test of indirect effect was significant $(.025, p<0.001)$, which accounted for slightly more than a half $(52 \%)$ of the total

\footnotetext{
${ }^{18}$ For this justice-involved sample, it is important to control for incarceration experience during the study period because it either directly or indirectly affects the changes in both fatherhood status and offending. Considering that the covariates in the PSM, by definition, should be measured before the change in the fatherhood status, it was not included in the previous propensity score matching procedure.
} 
Table 4 The effect of fatherhood transition on offending and other proposed mediators

\begin{tabular}{|c|c|c|c|c|c|c|c|c|}
\hline & \multicolumn{4}{|c|}{ Adolescents } & \multicolumn{4}{|c|}{ Young adults } \\
\hline & Estimate & Std. error & $t$ & $\operatorname{Pr}(>|t|)$ & Estimate & Std. error & $t$ & $\operatorname{Pr}(>|t|)$ \\
\hline \multicolumn{9}{|l|}{ Contemporaneous Effects } \\
\hline Offending (frequency) & 67.40 & $(15.95)$ & 4.22 & $* * *$ & -16.32 & $(19.25)$ & -0.85 & \\
\hline Aggressive & 2.64 & $(0.98)$ & 2.70 & $*$ & -4.41 & $(4.93)$ & -0.89 & \\
\hline Income-generating & 58.90 & $(14.65)$ & 4.02 & $* * *$ & -0.52 & (12.99) & -0.04 & \\
\hline Offending (variety) & 0.03 & $(0.01)$ & 2.40 & * & -0.01 & $(0.01)$ & -1.58 & \\
\hline Aggressive & 0.02 & $(0.01)$ & 1.46 & & -0.01 & $(0.01)$ & -1.39 & \\
\hline Income-generating & 0.04 & $(0.01)$ & 2.70 & $* *$ & -0.01 & $(0.01)$ & -0.64 & \\
\hline \multicolumn{9}{|l|}{ Lagged effects } \\
\hline Offending (frequency) & 84.79 & $(27.81)$ & 3.05 & $* *$ & -12.62 & $(19.46)$ & -0.65 & \\
\hline Aggressive & 0.73 & (1.79) & 0.41 & & -0.79 & (1.94) & -0.41 & \\
\hline Income-generating & 45.63 & $(22.88)$ & 2.00 & $*$ & -8.48 & $(16.33)$ & -0.52 & \\
\hline Offending (variety) & 0.04 & $(0.01)$ & 3.20 & $* *$ & -0.01 & $(0.01)$ & -1.14 & \\
\hline Aggressive & 0.03 & $(0.01)$ & 2.66 & $* *$ & -0.00 & $(0.01)$ & -0.02 & \\
\hline Income-generating & 0.04 & $(0.01)$ & 2.91 & $* *$ & -0.02 & $(0.01)$ & -1.86 & \\
\hline \multicolumn{9}{|l|}{ Proposed mediators } \\
\hline Aspiration for success & -0.03 & $(0.06)$ & -0.54 & & 0.12 & $(0.05)$ & 2.49 & $*$ \\
\hline Expectation for success & 0.02 & $(0.08)$ & 0.28 & & 0.24 & $(0.08)$ & 2.94 & $* *$ \\
\hline Motivation for success & 0.01 & $(0.06)$ & 0.17 & & 0.01 & $(0.06)$ & 0.14 & \\
\hline Personal cost & 0.02 & $(0.07)$ & 0.29 & & 0.02 & $(0.05)$ & 0.77 & \\
\hline Social cost & 0.03 & $(0.09)$ & 0.33 & & 0.02 & $(0.10)$ & 0.21 & \\
\hline Personal reward & -0.36 & $(0.25)$ & -1.47 & & -0.11 & $(0.19)$ & -0.59 & \\
\hline Unsupervised socializing & -0.18 & $(0.08)$ & -2.28 & $*$ & -0.27 & $(0.09)$ & -3.12 & $* *$ \\
\hline Exposure to violence & 0.78 & $(0.21)$ & 3.77 & $* * *$ & -0.54 & $(0.17)$ & -3.22 & $* *$ \\
\hline Peer behavior & 0.23 & $(0.09)$ & 2.65 & $* *$ & 0.01 & $(0.08)$ & 0.08 & \\
\hline Peer influence & 0.17 & $(0.07)$ & 2.27 & $*$ & 0.06 & $(0.06)$ & 1.00 & \\
\hline Peer resistance & -0.02 & $(0.06)$ & -0.30 & & -0.05 & $(0.04)$ & -1.13 & \\
\hline Gang involvement & 0.02 & $(0.03)$ & 0.67 & & -0.04 & $(0.03)$ & -1.57 & \\
\hline PSMI (self-reliance) & 0.03 & $(0.05)$ & 0.92 & & 0.05 & $(0.05)$ & 1.00 & \\
\hline PSMI (identity) & 0.05 & $(0.05)$ & -0.15 & & 0.09 & $(0.04)$ & 2.07 & $*$ \\
\hline PSMI (work orientation) & -0.01 & $(0.05)$ & 0.33 & & 0.05 & $(0.04)$ & 1.22 & \\
\hline
\end{tabular}

${ }^{*} p<0.05 ;{ }^{* *} p<0.01 ; * * * p<0.001$

effect. ${ }^{19}$ Specific indirect effects were $0.016(p<0.001)$ for exposure to violence and $0.009(p<0.01)$ for association with antisocial peer, respectively. Although PSM analyses (with the proposed mediators as outcomes) suggested that becoming a father during young adulthood has transformative potential for more positive life outcomes by significantly influencing the proposed mediators (aspiration/expectation for success, unsupervised socializing, exposure to violence, identity) as predicted by Laub and Sampson [1], mediation analysis was not conducted given that becoming a father

\footnotetext{
${ }^{19}$ Considering that conventional statistical tests of mediation tend to be underpowered due to the violation of the normality assumption [73], 95 and $99 \%$ CIs for the indirect effect estimators were created empirically using bootstrapping procedures. Using sampling with replacement, 1000 bootstrap samples were generated to calculate the bias-corrected percentiles of the rank-ordered estimates (see Preacher and Hayes 2004: 720-22).
} 


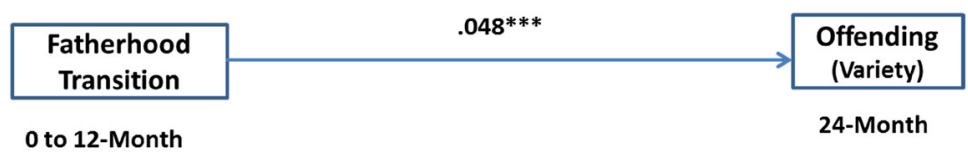

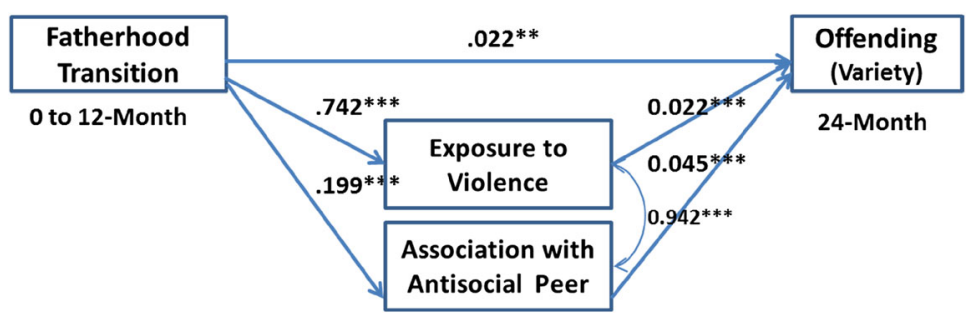

12-Month

$* * p<.01, * p<.05$

(Although not specified, these models were estimated on the matched sample after adjusting for the individual's propensity score of becoming a father and the time spent in facilities without access to community)

Fig. 2 Total, direct, and indirect effects of fatherhood transition on subsequent offending among adolescents

among young adults was not significantly associated with the reduced likelihood of future offending.

\section{Conclusions and Discussion}

Drawing on longitudinal panel data and appropriate analytic techniques to improve causal inference, this study provides some valuable insights into the impact of having a first child on subsequent offending behaviors and other aspects of life among serious male offenders during the critical period of making transitions into adulthood. The patterns observed in the current data help us understand why prior research has reached different conclusions - some find beneficial, some find harmful, and still others find no effect. Even after controlling for many potential confounders, the transition to fatherhood led to a significant increase in subsequent offending for teenagers. On the contrary, becoming a father was associated with reductions in offending among young adults, although its effects failed to reach the conventional threshold for statistical significance. These findings support the prediction from life course perspectives, which posit that the impact of salient life events is not homogeneous but varies substantially by the timing of a transition. In particular, a premature transition into adult roles and expectations tended not to be successfully embraced by the teen fathers and hence failed to trigger the mediating processes for criminal desistance. Teen fathers neither stayed away from their immediate criminogenic environment nor began to view themselves and their life goals differently after becoming a father. Rather, too early transition into fatherhood aggravated teen fathers' life circumstances possibly by exposing them to the situations and relationship contexts where crime and violence were prevalent. Thus, it surely did not have a "knifing-off" potential of restructuring everyday routines, one of the most immediate and visible changes that emerge after experiencing turning points ([1]: 145). Considering that such criminogenic effect was most pronounced for income-generating offending, it is plausible to assume that teen 
fathers are more likely to experience financial hardship and attempt to generate income through illegal channels such as stealing or drug dealing. These findings contrast sharply with other empirical studies that documented strong and significant crime reduction effects of early parenthood transition, especially among disadvantaged minority women (e.g., $[15,19])$. However, the results from the young adult sample were consistent with the predictions from the existing literature suggesting that fatherhood transition has the potential to trigger the processes of criminal desistance at multiple domains of life. In particular, having a first child during early adulthood increased the fathers' motivation to achieve success and commitment to conformity, pulled them away from immediate environments conducive to crime, and even changed their sense of self-esteem and responsibility. Although the current study failed to detect any significant crime reduction effect of the fatherhood transition among young adult offenders, the effect of fatherhood may take time to appear as the investments in social bond grow, the stakes in conformity increase, and self-identity gradually changes from the one that characterizes delinquents to the other that represents responsible fathers after taking on stable parenting roles and responsibilities. Further understanding of not just how timely arrival of turning points exerts influence on the reduction in subsequent offending but also why untimely transitions do not inhibit or even facilitate future offending would be fundamental to a more complete understanding of criminal desistance.

The present study has several limitations. The current data do not allow for an investigation of more nuanced and contextualized meanings of fatherhood transition due to lack of detailed information about the intention of the childbirth or the nature and quality of relationship contexts with romantic partners and children. Indeed, it is extremely difficult to tease out the meaning of the timing effect because it is inherently interconnected with the subjective elements of change such as the initial motivation or readiness for change. For example, the childbirth during adolescence is far less likely to be an intended outcome occurring within the context of good and stable relationship with partners than having a child during adulthood. In particular, one of the unresolved issues in the turning point literature is whether such life events occur randomly to an individual and then cause individual's subsequent internal/external changes, or they are more likely to be outcomes of a deliberate choice made by an individual who already has motivation or intention to change and benefit from adulthood transitions. For example, although it is widely accepted that good marriage and employment cause subsequent desistance processes [1], it is also plausible to assume that some already had the initial motivation to change ("make good": [75]; "crystallization of discontent": [40]) or at least were more open to change ("cognitive and emotional transformation": $[38,39])$ and have been engaging in "up-front work" to better their lives even before the experience of turning points or hooks for change. Indeed, few people get married or employed without deliberate intentions to do so. Considering that the transition to parenthood in this relatively young sample involves more randomness (e.g., in 2006, the percentages of unintended pregnancy for women aged 15-19 and 20-24 were 82 and $64 \%$, respectively: [72]) than other transitions, the study of fatherhood as a turning point is better suited for approximating experimental conditions by adopting a "potential outcome" model. Just like other multivariate models, however, PSM also assumes that there are no unobserved differences between the two study groups. When additional differences exist such as individual's readiness or agentic motivation to change, 
the validity of findings in this study would be rendered questionable. Considering that such internal changes are time-varying in nature, we cannot simply eliminate this omitted variable bias with fixed effects approaches, but should explicitly measure and incorporate them into the covariate pool or causal diagram of the model. Future research should more explicitly assess whether parenthood transition is an exogenous factor which initiates desistance processes or rather an endogenous condition which individuals - with high motivation to change - select into.

Acknowledgments This research was supported, in part, by The Professional Staff Congress-City University of New York (PSC-CUNY) Research Award Program 46. The author would like to thank Ray Paternoster, Olive Liu, and three anonymous reviewers for their suggestions and comments.

\section{References}

1. Laub, J. H., \& Sampson, R. J. (2003). Shared beginnings, divergent lives: delinquent boys to age 70. Cambridge: Harvard University Press.

2. Sampson, R. J., \& Laub, H. J. (1993). Crime in the making: pathways and turning points through life. Cambridge: Harvard University Press.

3. Bersani, B., Laub, J. H., \& Nieuwbeerta, P. (2009). Marriage and desistance from crime in the Netherlands: do gender and socio-historical context matter?'. Journal of Quantitative Criminology, 25, 3-24.

4. Blokland, A. A. J., \& Nieuwbeerta, P. (2005). The effects of life circumstances on longitudinal trajectories of offending. Criminology, 4, 1203-1240.

5. King, R., Massoglia, M., \& MacMillan, R. (2007). The context of marriage and crime: gender, the propensity to marry, and offending in early adulthood. Criminology, 45, 33-66.

6. Sampson, R. J., Laub, J. H., \& Wimer, C. (2006). Does marriage reduce crime? A counterfactual approach to within-individual causal effects. Criminology, 44, 465-508.

7. Shover, N. (1996). Great pretenders: pursuits and careers of persistent thieves. Boulder: Westview Press.

8. Skardhamar, T., \& Savolainen, J. (2014). Changes in criminal offending around the time of job entry: a study of employment and desistance. Criminology, 52, 263-291.

9. Uggen, C. (2000). Work as a turning point in the life course of criminals: a duration model of age, employment, and recidivism. American Sociological Review, 67, 529-546.

10. Verbruggen, J., Blokland, A., \& Van der Geest, V. R. (2012). Effects of employment and unemployment on serious offending in a high-risk sample of men and women from ages 18 to 32 in the Netherlands. British Journal of Criminology, 52(5), 845-869.

11. Elder, G. H., Jr. (1986). Military times and turning points in men's lives. Developmental Psychology, 22, 233-245.

12. Sampson, R. J., \& Laub, H. J. (1996). Socioeconomic achievement in the life course of disadvantaged men: military service as a turning point, circa 1940-1965. American Sociological Review, 61, 347-367.

13. Melde, C., \& Esbensen, F. (2011). Gang membership as a turning point in the life course. Criminology, 49, 513-552.

14. Sweeten, G., Bushway, S. D., \& Paternoster, R. (2009). Does dropping out of school mean dropping into delinquency? Criminology, 47(1): 47-91.

15. Kreager, D. A., Matsueda, R. L., \& Erosheva, E. A. (2010). Motherhood and criminal desistance in disadvantaged neighborhoods. Criminology, 48(1), 221-258.

16. Monsbakken, C. W., Lyngstad, T. H., \& Skardhamar, T. (2013). Crime and the transition to parenthood: the role of sex and relationship context. British Journal of Criminology, 53, 129-148.

17. Savolainen, J. (2009). Work, family and criminal desistance. British Journal of Criminology, 49, $285-304$.

18. Elder, G. H., Jr. (1985). Life course dynamics: trajectories and transitions. Ithaca: Cornell University Press.

19. Edin, K., \& Kefalas, M. (2005). Promises I can keep: why poor women put motherhood before marriage. Berkeley: University of California Press.

20. Edin, K., Nelson, T. J., \& Paranal, R. (2004). Fatherhood and incarceration as potential turning points in the criminal careers of unskilled men. In M. Pattillo, D. Weiman, \& B. Western (Eds.), Imprisoning America: the social effects of massive incarceration (pp. 46-75). New York: Russell Sage Foundation. 
21. Eggebeen, D. J., \& Knoester, C. (2001). Does fatherhood matter for men? Journal of Marriage and Family, 63, 381-393.

22. Farrington, D. P., \& West, D. J. (1995). Effects of marriage, separation, and children in offending by adult males. Current Perspectives on Aging and the Life Cycle, 4, 249-281.

23. Giordano, P. C., Seffrin, P. M., Manning, W. D., \& Longmore, M. A. (2011). Parenthood and crime: the role of wantedness, relationships with partners, and SES. Journal of Criminal Justice, 39, 405-416.

24. Zoutewelle-Terovan, M. V., Van der Geest, V. R., Liefbroer, A. C., \& Bijleveld, C. (2012). Criminality and family formation: effects of marriage and parenthood on criminal behavior for men and women. Crime and Delinquency, 60(8), 1209-1234.

25. Elder, G. H., Jr. (1998). The life course as developmental theory. Child Development, 69, 1-12.

26. Raley, R. K. (2000). Recent trends and differentials in marriage and cohabitation: the United States. In L. J. W. Hawthorne (Ed.), The ties that bind: perspectives on marriage and cohabitation (pp. 19-39). NY: Aldine de Gruyter.

27. Graefe, D. R., \& Lichter, D. T. (2002). Marriage among unwed mothers: whites, blacks and Hispanics compared. Perspectives on Sexual and Reproductive Health, 34(6), 286-293.

28. Booth, A., Rustenbach, E., \& McHale, S. (2008). Early family transitions and depressive symptom changes from adolescence to young adulthood. Journal of Marriage and the Family, 70, 3-14.

29. Draper, J. (2003). Men's passage to fatherhood: an analysis of the contemporary relevance of transition theory. Nursing Inquiry, 10(1), 66-78.

30. Gauthier, A. H., \& Furstenberg, F. F. (2002). The transition to adulthood: a time use perspective. Annals of the American Academy of Political and Social Science, 580, 153-171.

31. Edin, K., \& Nelson, T. J. (2013). Doing the best I can: fatherhood in the inner city. London: University of California Press.

32. Edin, K., Tach, L., \& Mincy, R. (2009). Claiming fatherhood, race and the dynamics of paternal involvement among unmarried men. The Annals of the American Academy of Political and Social Science, 621, 149-177.

33. Hamer, J. F. (2001). What it means to be daddy: fatherhood for black men living away from their children. New York: Columbia University Press.

34. Waller, M. R. (2002). My baby's father: unwed parents and paternal responsibilities. Ithaca: Cornell University Press.

35. Tach, L., \& Edin, K. (2011). Young disadvantaged men as fathers. Annals of the American Academy of Political and Social Science, 635: 76-94.

36. Theobald, D., Farrington, D. P., \& Piquero, A. R. (2015). Does the birth of a first child reduce the father's offending? Australian \& New Zealand Journal of Criminology, 48(1), 3-23.

37. Glueck, S., \& Glueck, E. (1945). After-conduct of discharged offenders. London: Macmillan.

38. Giordano, P. C., Cernkovich, S. A., \& Rudolph, J. L. (2002). Gender, crime, and desistance: toward a theory of cognitive transformation. American Journal of Sociology, 107, 990-1064.

39. Giordano, P. C., Schroeder, R. D., \& Cernkovich, S. A. (2007). Emotions and crime over the life-course: a neo-median perspective on criminal continuity and change. American Journal of Sociology, 112, 1603-1661.

40. Paternoster, R., \& Bushway, S. (2009). Desistance and the feared self: toward an identity theory of desistance. Journal of Criminal Law and Criminology, 99, 1103-1156.

41. Höfner, C., Schadler, C., \& Richter, R. (2011). When men become fathers: men's identity at the transition to parenthood. Journal of Comparative Family Studies, 42(5), 669-686.

42. Matsueda, R. L., \& Heimer, K. (1997). A symbolic interactionist theory of role-transitions, role-commitments, and delinquency. In: Developmental theories of crime and delinquency, advances in criminological theory, vol. 7, Thornberry, T. P. (eds.). New Brunswick.

43. Rosenbaum, P., \& Rubin, D. (1983). The central role of the propensity score in observational studies for causal effects. Biometrika, 70, 41-55.

44. Apel, R., \& Sweeten, G. (2010). Propensity score matching in criminology and criminal justice. In A. R. Piquero \& D. Weisburd (Eds.), Handbook of quantitative criminology (pp. 543-562). New York: Springer.

45. Loughran, T. A., \& Mulvey, E. P. (2010). Estimating treatment effects: Matching quantification to the question. Handbook of Quantitative Criminology, 163-180.

46. Hsiao, C. (2003). Analysis of panel data. New York: Cambridge University Press.

47. Wooldridge, J. M. (2002). Econometric analysis of cross section and panel data. Cambridge: MIT Press.

48. Bollen, K. A., \& Curran, P. J. (2006). Latent curve models: a structural equation perspective. Hoboken: Wiley.

49. Raudenbush, S. W., \& Bryk, A. S. (2002). Hierarchical linear models. Thousand Oaks: Sage. 
50. Leuven, E., \& Sianesi, B. (2003). PSMATCH2: Stata module to perform full Mahalanobis and propensity score matching, common support graphing, and covariate imbalance testing. Boston College Department of Economics, Statistical Software Components.

51. Diamond, A., \& Sekhon, J. S. (2013). Genetic matching for estimating causal effects: a general multivariate matching method for achieving balance in observational studies. The Review of Economics and Statistics, 95(3), 932-945.

52. Ho, D., Imai, K., King, G., \& Stuart, E. (2007). Matching as nonparametric preprocessing for reducing model dependence in parametric causal inference. Political Analysis, 15, 199-236.

53. Ho, D., Imai, K., King, G., \& Stuart, E. (2011). MatchIt: nonparametric preprocessing for parametric causal inference. Journal of Statistical Software, 42(8), 1-28.

54. Precher, K. J., \& Hayes, A. F. (2008). Asymptotic and resampling strategies for assessing and comparing indirect effects in multiple mediator models. Behavior Research Methods, 40, 879-891.

55. Guo, S., \& Fraser, M. W. (2015). Propensity score analysis: statistical methods and applications. Thousand Oaks: Sage Publications, Inc.

56. Hamilton, B. E., Martin, J. A., \& Ventura, S. J. (2013). Births: Preliminary data for 2012. Hyattsville: National Center for Health Statistics. Available http://www.cdc.gov/nchs/data/nvsr/nvsr62/nvsr62_03.pdf.

57. Martin, J. A., Hamilton, B. E., Osterman, Michelle J.K., Curtin, S. C., \& Mathews, T.J.(2012). Birth: final data for 2012. National Vital Statistics Reports 62 (9).

58. Kirby, D. (2007). Emerging answers research findings on programs to reduce teen pregnancy and sexually transmitted diseases. Washington, DC: The National Campaign to Prevent Teen and Unplanned Pregnancy.

59. Bryson, A., Dorsett, R., \& Purdon, S. (2002) The Use of Propensity Score Matching in the Evaluation of Labour Market Policies. Working Paper No. 4, Department for Work and Pensions.

60. Rubin, D. B., \& Thomas, N. (1996). Matching using estimated propensity scores: relating theory to practice. Biometrics, 52, 249-264.

61. Dehejia, R. H., \& Wahba, S. (2002). Propensity score-matching methods for nonexperimental causal studies. The Review of Economics and Statistics, 84(1), 151-161.

62. Caliendo, M., \& Kopeinig, S. (2008). Some practical guidance for the implementation of propensity score matching. Journal of Economic Surveys, 22, 31-72.

63. Imai, K., King, G., \& Stuart, E. A. (2006). Misunderstandings among experimentalists and observationalists: balance test fallacies in causal inference. Journal of the Royal Statistical Society: Series A, 171, 481-502.

64. Austine, P. C. (2011). An introduction to propensity score methods for reducing the effects of confounding in observational studies. Multivariate Behavioral Research, 46(3), 399-424.

65. Imai, K., King, G., \& Stuart, E. A. (2008). Misunderstanding between experimentalists and observationalists about causal inference. Journal of the Royal Statistical Society, Series A, 171(2), 481-502.

66. Cochran, W. G. (1968). The effectiveness of adjustment by subclassification in removing bias in observational studies. Biometrics, 24, 295-313.

67. Schafer, J. L., \& Kang, J. (2008). Average causal effects from nonrandomized studies: a practical guide and simulated example. Psychological Methods, 13(4), 279-313.

68. Shadish, W. R., Clark, M. H., \& Steiner, P. M. (2008). Can nonrandomized experiments yield accurate answers?: a randomized experiment comparing random and nonrandom assignments. Journal of the American Statistical Association, 103(484), 1334-1344.

69. Klein, J. D. (2005). Adolescent pregnancy: current trends and issues. Pediatrics, 116, 281-286.

70. Hoffman, S. D. (2008). Consequences of teen childbearing for mothers: updated estimates of the consequences of teen childbearing for mothers. In S. D. Hoffman \& R. A. Maynard (Eds.), Kids having kids: economic costs and social consequences of teen pregnancy (2nd ed., pp. 74-92). Washington, DC: The Urban Institute Press.

71. Nurse, A. M. (2002). Fatherhood arrested: parenting from within the juvenile justice system. Nashville: Vanderbilt University Press.

72. Finer, L. B., \& Zolna, M. R. (2011). Unintended pregnancy in the United States: incidence and disparities, 2006. Contraception, 84(5), 478-485.

73. Bollen, K. A., \& Stein, R. (1990). Direct and indirect effects: classical and bootstrap estimates of variability. Sociological Methodology, 20, 115-140.

74. Muthen, L. K., \& Muthen, B. O. (1998-2013). Mplus version 7.11. Mplus user's guide. in: Muthén \& Muthén (eds.) Los Angeles, CA

75. Maruna, S. (2001). Making good: how ex-convicts reform and build their lives. Washington, D.C.: American Psychological Association Books. 